\title{
Vertical Wave Impacts on Offshore Wind Turbine Inspection Platforms
}

\author{
Bredmose, Henrik; Jacobsen, Niels Gjøl
}

Published in:

Proceedings of the ASME 2011 30th International Conference on Ocean, Offshore and Arctic Engineering

Publication date:

2011

Document Version

Publisher's PDF, also known as Version of record

Link back to DTU Orbit

Citation (APA):

Bredmose, H., \& Jacobsen, N. G. (2011). Vertical Wave Impacts on Offshore Wind Turbine Inspection Platforms. In Proceedings of the ASME 2011 30th International Conference on Ocean, Offshore and Arctic Engineering (Vol. 5, pp. 645-654). American Society of Mechanical Engineers.

\section{General rights}

Copyright and moral rights for the publications made accessible in the public portal are retained by the authors and/or other copyright owners and it is a condition of accessing publications that users recognise and abide by the legal requirements associated with these rights.

- Users may download and print one copy of any publication from the public portal for the purpose of private study or research.

- You may not further distribute the material or use it for any profit-making activity or commercial gain

- You may freely distribute the URL identifying the publication in the public portal

If you believe that this document breaches copyright please contact us providing details, and we will remove access to the work immediately and investigate your claim. 


\section{Proceedings of the ASME 2011 30th International Conference on Ocean, Offshore and Arctic Engineering OMAE2011}

June 19-24, 2011, Rotterdam, The Netherlands

\section{OMAE2011-49785}

\section{VERTICAL WAVE IMPACTS ON OFFSHORE WIND TURBINE INSPECTION PLATFORMS}

\author{
Henrik Bredmose \\ DTU Mechanical Engineering \\ DK-2800 Kgs. Lyngby \\ Denmark \\ Email: hbr@mek.dtu.dk
}

\author{
Niels G. Jacobsen \\ DTU Mechanical Engineering \\ DK-2800 Kgs. Lyngby \\ Denmark \\ Email: ngja@mek.dtu.dk
}

\begin{abstract}
Breaking wave impacts on a monopile at $20 \mathrm{~m}$ depth are computed with a VOF (Volume Of Fluid) method. The impacting waves are generated by the second-order focused wave group technique, to obtain waves that break at the position of the monopile. The subsequent impact from the vertical run-up flow on a horizontal inspection platform is computed for five different platform levels.

The computational results show details of monopile impact such as slamming pressures from the overturning wave front and the formation of run-up flow. The results show that vertical platform impacts can occur at $20 \mathrm{~m}$ water depth. The dependence of the vertical platform load to the platform level is discussed. Attention is given to the significant downward force that occur after the upward force associated with the vertical impact. The effect of the numerical resolution on the results is assessed. The position of wave overturning is found to be influenced by the grid resolution. For the lowest platform levels, the vertical impact is found to contribute to the peak values of in-line force and overturning moment.
\end{abstract}

\section{INTRODUCTION}

The majority of todays offshore wind turbine farms are placed on monopile foundations. The foundations are subject to the harsh environment at sea, including violent impacts from breaking and near-breaking waves. Such impacts are also associated with strong run-up along the sides of the monopile. At the Danish Horns Reef 1 wind farm, the subsequent impact from these vertical flows lead to severe damage on the horizontal inspection platforms (Damsgaard et al [1]). The platforms, constructed from gratings, were placed $9.0 \mathrm{~m}$ above the mean water level and were either blown away from their support frames, or the entire support framework was blown away (Frigaard et al [2]).

The unexpected loads on the platforms have motivated a number of laboratory studies on the run-up on monopiles [1,3,4]) and the associated vertical loads $[2,5,6]$. Gravesen [7] devised a design procedure based on the run-up heights.

CFD computation of wave impacts on monopiles have been undertaken by several authors, with a main focus on the in-line force and overturning moment. Christensen et al [8] presented results for regular wave forcing of a monopile on a sloping sea bed. Bredmose et al [9] conducted a numerical reproduction of two extreme events from a physical test of wave impacts on a gravity base wind turbine foundation. One of the events lead to a wave-in-deck type impact on the inspection platform, where the interaction with the structure caused the body of the main wave to impact on the platform. This lead to a strong overturning moment, associated with the strong pressure that occurred in the corner between the vertical pile wall and the horizontal platform.

While the average depth at Horns Reef 1 is up to $14 \mathrm{~m}$, the installation depth for many newer offshore wind farms in the North Sea is $20-30 \mathrm{~m}$. This motivates an investigation into the possibility for similar violent platform impacts at these larger depths. For example, the shape of breaking wave fronts is dif- 
ferent in shallow and intermediate depth. While in shallow conditions, the height of the overturning crest can span a large fraction of the total depth, the breaking in deeper water is usually a more local 'white-capping' phenomenon at the front of the wave crest. For design purposes, the magnitude of the vertical impact force and its dependence on the vertical level of the platform is important.

In the present paper, 3D CFD computations of breaking wave impacts, run-up and subsequent platform impact are presented at a depth of $20 \mathrm{~m}$. The study is a continuation from Bredmose \& Jacobsen [10] who studied breaking wave impacts from focused wave groups on a monopile with a diameter of $5 \mathrm{~m}$. In the new study, the incident wave description is extended from linear theory to second order, to achieve a more steady rise in crest height up to the focus point. Computations of wave impact, run-up and subsequent platform impact are undertaken for 5 different platform levels. At the highest level, the platform is barely reached by the run-up flow, while at the lowest level, the impact is of the wave-in-deck type, where the main body of the wave touches the platform. Results for vertical force on the platform as function of platform level are presented. Further, the contribution from the platform-impact to the global in-line force and overturning moment is discussed. The grid dependence of the results is assessed in terms of a reference computation on a refined grid. The results indicate that the position of wave overturning is influenced by the grid resolution.

Despite this influence from the numerical grid, the results for the present wave impacts show that at a depth of $20 \mathrm{~m}$, the vertical impact force varies strongly with the platform level. For levels that exceed $9 \mathrm{~m}$, the computed vertical peak forces are of magnitude $51 \mathrm{kN}$ or smaller. For a platform level of $7.09 \mathrm{~m}$, a vertical peak force of $95 \mathrm{kN}$ is found, while at a platform level of $6.04 \mathrm{~m}$, the vertical force is $380 \mathrm{kN}$. For this platform level the pressures from the vertical impact contribute significantly to the peak in-line force and overturning moment.

\section{PHYSICAL TEST CASE AND WAVE CLIMATE}

Newer offshore wind farms in the North Sea are typically placed in less shallow conditions than at Horns Reef 1. For this reason a depth of $20 \mathrm{~m}$ is chosen for the present study. While a sloping sea bed in shallow water is known to induce wave breaking, we here choose a horizontal bed. Hereby, the only mechanism to make the waves break is the focusing process, where a number of irregular wave crests coincide at one location and forms a large-amplitude nonlinear wave.

We note that this method may not generate the most severe breaking events. On the other hand, by studying events that only break due to the focus effect, we remove one parameter from the definition of the physical test cases. Further it is interesting to find out if the focusing effect alone can lead to impacts with severe vertical loads.

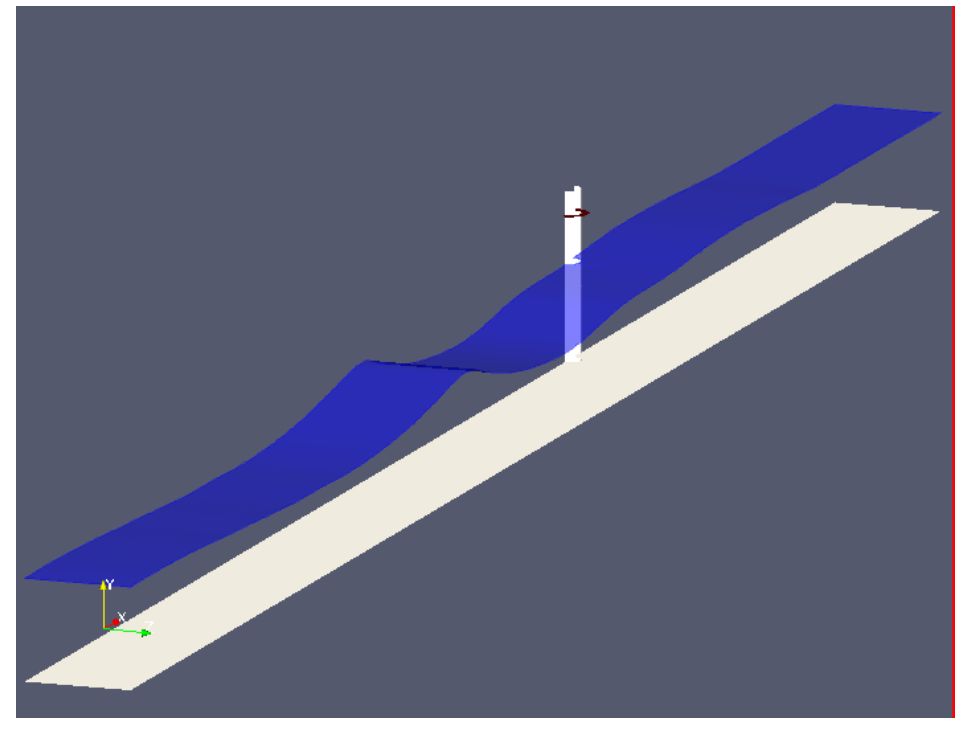

FIGURE 1. The physical domain. Only the right half of the domain is shown due to symmetry. The platform is positioned $10 \mathrm{~m}$ above the mean water level and marked by red colour.

The physical domain is shown in figure 1. Only half of the domain is shown due to symmetry in the lateral direction. The monopile has a diameter of $D=5.0 \mathrm{~m}$. The inspection platform is placed $10 \mathrm{~m}$ above the mean water level with an outer diameter of $8.0 \mathrm{~m}$. In the present study, the platform is considered to be fully impermeable and five different platform levels of $z_{p}=(6.04,7.08,8.96,10.0,12.08) \mathrm{m}$, measured upwards from the still water level are chosen for computation.

\section{Second-order focused wave groups}

A JONSWAP spectrum with a peak period of $T_{p}=13 \mathrm{~s}$ was chosen. The impacting waves were achieved in terms of focused wave groups, where all the linear components of the discretized spectrum are phase-tuned to have a wave crest at the focus location $x_{0}$ at the focus time $t_{0}$. For the free surface elevation $\eta$ and the velocity potential $\phi$, the linear part can thereby be written

$$
\begin{aligned}
\eta^{(1)}(x, t)= & \sum_{p=1}^{N} a_{p} \cos \left(k_{p}\left(x-x_{0}\right)-\omega_{p}\left(t-t_{0}\right)\right) \\
\phi^{(1)}(x, z, t)= & \sum_{p=1}^{N} b_{p} \frac{\cosh k_{p}(h+z)}{\cosh k_{p} h} \\
& \quad \times \sin \left(k_{p}\left(x-x_{0}\right)-\omega_{p}\left(t-t_{0}\right)\right)
\end{aligned}
$$

where $\left(a_{p}, b_{p}\right)$ are the spectral amplitudes at radian frequency $\omega_{p}, k_{p}$ is the associated linear wave number and $N$ is the number of frequencies. The vertical coordinate $z$ and $\eta$ are measured up- 
wards from the still water level and $h$ is the still water depth. The spectral amplitudes $\left(a_{p}, b_{p}\right)$ are connected through the relation $b_{p}=g a_{p} / \omega_{p}$ where $g$ is the acceleration of gravity.

Bredmose \& Jacobsen [10] used the focused wave group technique to generate breaking wave impacts on a monopile foundation. The first-order wave field (1) was enforced at a distance from the monopile and propagated into the domain under influence of wave nonlinearity. As discussed by numerous authors (e.g. [11], [12]), the enforcement of only the linear wave spectrum leads to generation of spurious second-order waves at the sum- and difference frequencies of the linear components. While the true second-order solution consists of wave components at these frequencies that are phase-locked (bound) to the linear waves, enforcement of only the linear spectrum yields a second-order wave field of both bound and free waves. In this situation, the low-frequency components may cause a timedependent modulation of the mean water level through the domain which can potentially disturb the focusing effect by induction of premature breaking. Such premature breaking was observed by Bredmose \& Jacobsen [10], leading to a non-smooth transition towards a fully breaking wave.

To overcome the problem of spurious long waves, secondorder focused wave groups were applied in the present study. The second-order solution is given by Sharma \& Dean [13]. For the first-order field (1), the solution for the free surface elevation reads

$$
\begin{aligned}
\eta^{(2)}(x, t)= & \frac{1}{4} \sum_{i=1}^{N} \sum_{j=1}^{N}[ \\
& T_{i j}^{-} a_{i} a_{j} \cos \left(\left(k_{i}-k_{j}\right)\left(x-x_{0}\right)-\left(\omega_{i}-\omega_{j}\right)\left(t-t_{0}\right)\right) \\
+ & \left.T_{i j}^{+} a_{i} a_{j} \cos \left(\left(k_{i}+k_{j}\right)\left(x-x_{0}\right)-\left(\omega_{i}+\omega_{j}\right)\left(t-t_{0}\right)\right)\right]
\end{aligned}
$$

where the kernel functions $T_{i j}^{-}, T_{i j}^{+}$depend on the wave numbers and radian frequencies for components $i$ and $j$ and are given in Sharma \& Dean [13]. A similar solution for the second-order velocity potential can be found in this paper too.

The spectral amplitudes $a_{p}$ applied in the present computations are shown in figure 2. The plot shows the linear as well as the second-order amplitudes of the free surface elevation. A cutoff frequency of $0.20 \mathrm{~Hz}$ was applied. Further, the linear wave spectrum was discretized with only 16 components, to reduce the computational effort for the double summation in (3). Further, the symmetry in $(i, j)$ was utilised to reduce the summation range by a factor of two.

Due to the special choice of phases for the components of the focused wave group, see (1), all the spectral amplitudes are real. Figure 2 further illustrates that the second-order sum-frequency components have positive amplitudes, while the differencefrequency components have negative amplitudes. Thus the long bound waves associated with the focused wave group has a wave

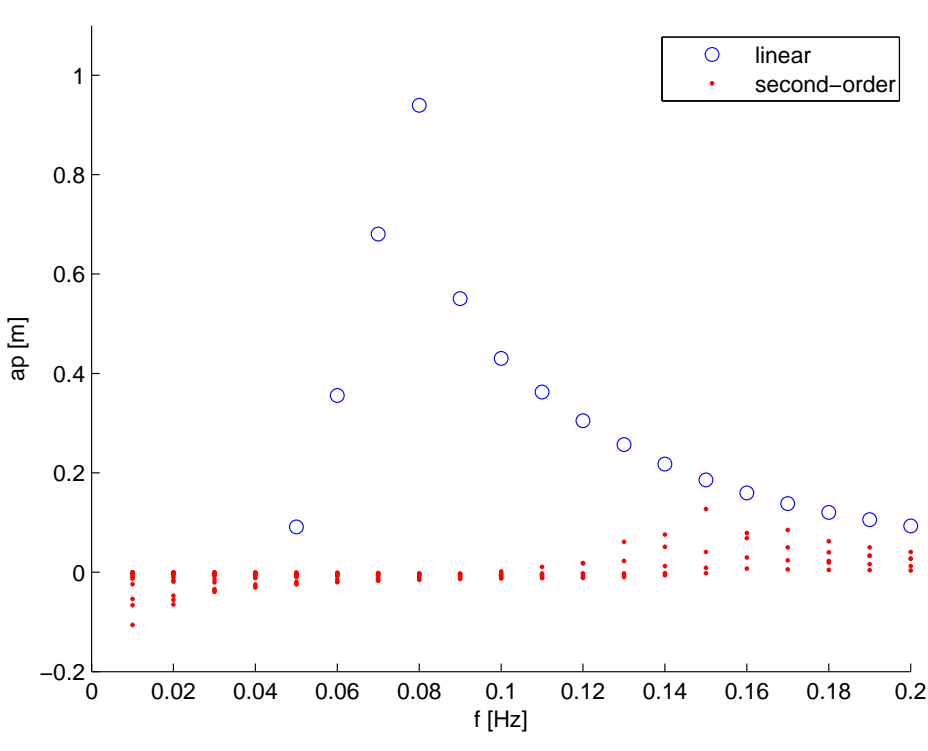

FIGURE 2. Spectral amplitudes of the incident wave field. Linear and second-order components.

trough in the focus point, while the linear spectrum and the super harmonic bound waves have a crest.

\section{COMPUTATIONAL MODEL}

The numerical model is a Navier-Stokes solver for the incompressible two-phase flow of water and air in a threedimensional domain. The solver is part of the open source CFD

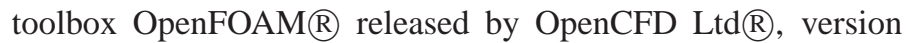
1.5. The interface between water and air is represented through the VOF (Volume Of Fluid) technique (Hirt\&Nichols) [14] that allows computation of wave overturning, wave breaking and runup. A special toolbox for wave generation has been developed to allow numerical generation of a range of wave theories. Details on this toolbox and its validation on standard test cases can be found in Jacobsen [15]

The computational domain is identical to the physical domain of figure 1 and was discretized with a grid of 691000 cells in 22 blocks. A global coordinate system was defined with origin at the still water crossing with the monopile centre and with the $x$-axis pointing in the direction of wave propagation. The grid is shown in figure 3 and was gradually refined from the offshore boundary towards the monopile. In the vertical direction, a quite coarse grid spacing was applied close to the sea bed, while the region from $z=-5 \mathrm{~m}$ to the upper boundary at $z=15 \mathrm{~m}$ was discretized with uniform spacing at a finer resolution. In this region the computational cells at the face of the monopile had a size of approximately $\mathrm{d} r \times r \mathrm{~d} \theta \times \mathrm{d} z=(0.12 \times 0.18 \times 0.21) \mathrm{m}^{3}$. Alternate grids for different platform levels were obtained by further 


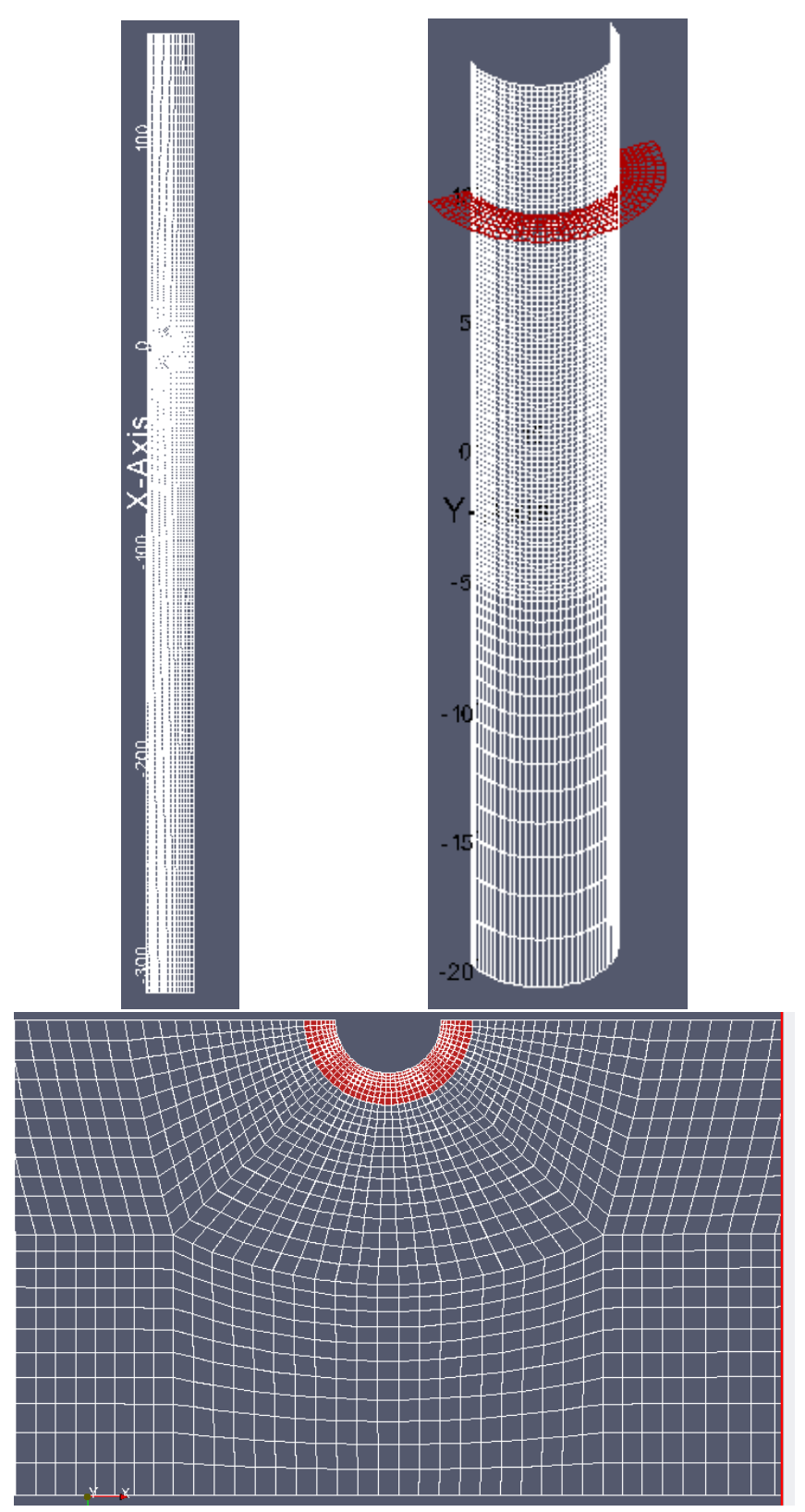

FIGURE 3. Numerical grid for $z_{p}=10 \mathrm{~m}$. Top left: Top view of full grid. Top right: Side view of the monopile and platform with vertical discretization. Bottom: Close-up on monopile and platform. The platform is marked by red colour.

addition of an internal wall boundary between two layers of cells at the platform level and with a horizontal extent equal to the platform geometry. Hereby the grids for all platform levels were identical except for the placement of the platform. This way of grid construction is the reason for the odd values of platform level of $(12.08,10.0,8.96,7.08,6.04) \mathrm{m}$. Slip-wall conditions
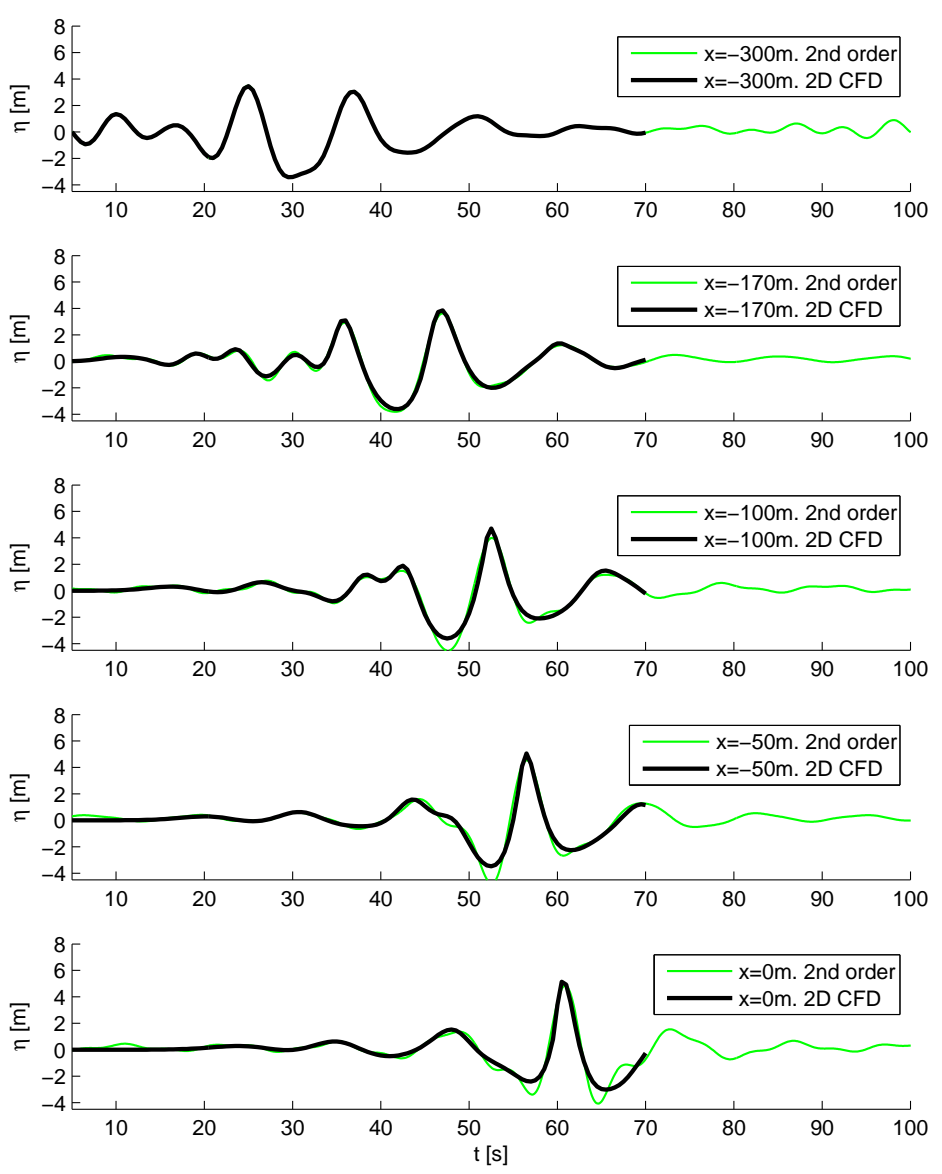

FIGURE 4. Incident wave field. Comparison of CFD solution and second-order theory.

were applied at the sea bed, the lateral boundaries, the monopile wall and the under-side of the platform. At the top boundary an outlet condition that allows water and air to leave the computational domain was applied.

The incident waves were generated inside a relaxation zone that stretches from $x=-312.5 \mathrm{~m}$ to $x=-172.5 \mathrm{~m}$, which is about one wave length. Within this zone, the incident wave field (1)-(3) was enforced after each numerical time step according to the update formula

$$
\psi_{\text {updated }}=\alpha \psi_{\text {target }}+(1-\alpha) \psi_{\text {computed }}
$$

where $\psi$ represents the velocity and voids ratio fields and $\psi_{\text {target }}$ is the desired incident wave field. The coefficient $\alpha$ is varied smoothly from unity at the offshore end of the relaxation zone to zero at the inner end of the zone. Behind the monopile, from $x=52.5 \mathrm{~m}$ to the downstream boundary at $x=152.5$, a similar relaxation zone with a target solution of still water was applied 

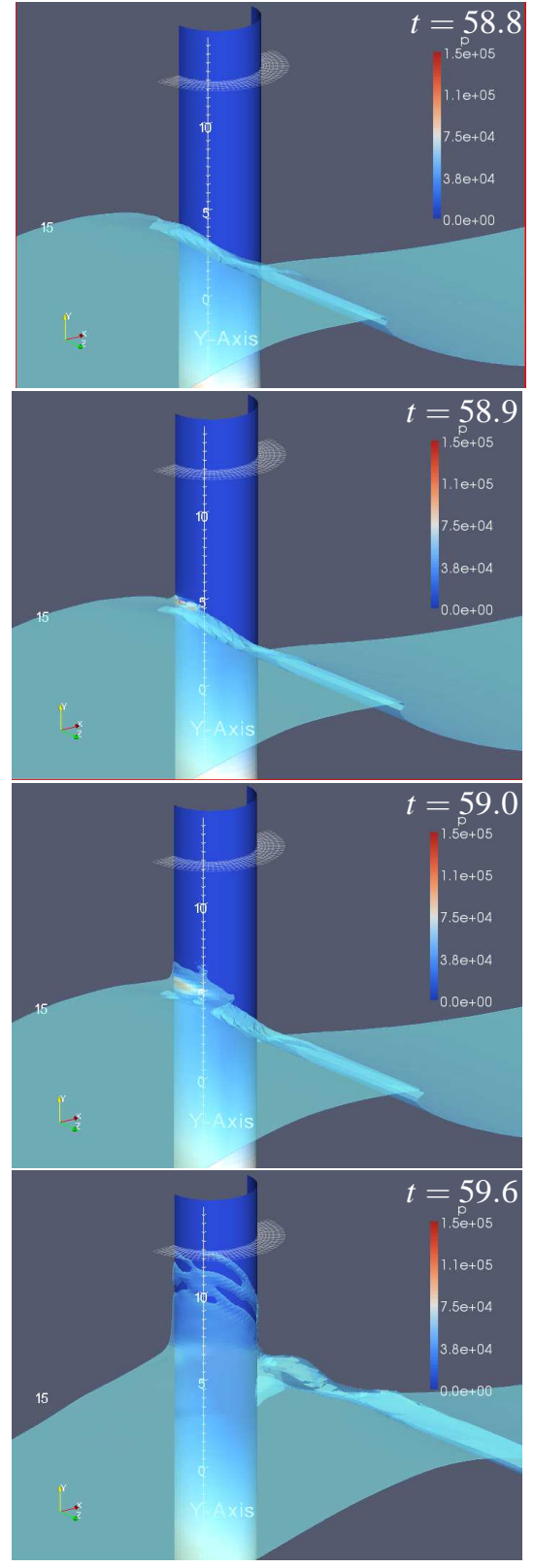

FIGURE 5. Snapshots of free surface and pressure field at cylinder wall and deck during impact for $z_{p}=12.08 \mathrm{~m}$. The colours show the pressure in $[\mathrm{Pa}]$.

to absorb the waves.

\section{RESULTS}

\section{Incident wave field}

Prior to the 3D computations, 2D computations of the incident wave field were carried out. With the present discretization
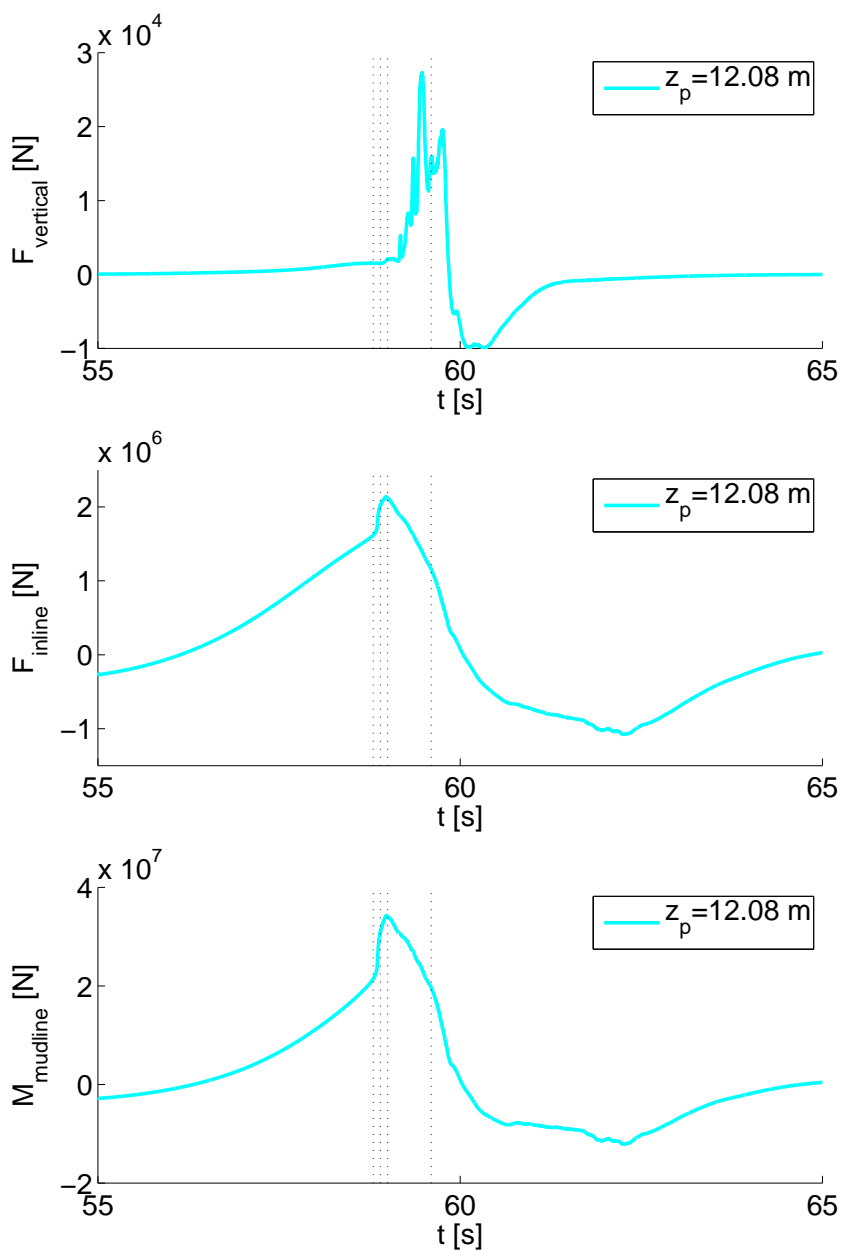

FIGURE 6. Time series for vertical force on platform (upper panel), in-line force (middle panel) and overturning moment (lower panel). $z_{p}=12.08 \mathrm{~m}$. Time instants for snapshots in figure 5 are marked by vertical dotted lines.

of the spectrum, a focus point of $x=0 \mathrm{~m}$ at $t=60 \mathrm{~s}$ was chosen and the amplitude of the linear signal was adjusted until the second-order boundary condition lead to a wave that overturned and initiated wave breaking at the position of the monopile. Time series of the resulting wave field are shown in figure 4 for five different positions in the domain. The plots also show the secondorder prediction of the wave field offered by (1)-(3). The two first positions at $x=(-300,-170) \mathrm{m}$ are placed at the upstream end of the offshore relaxation zone and just outside the relaxation zone, respectively. For both positions a good match between the second-order signal and the computational wave field is seen. Further into the domain, at $x=(-100,-50) \mathrm{m}$, a good match is observed for the smaller waves and for the main crest of the wave group. At these locations, however, the troughs of the CFD results are less deep than for the second-order solution. These ob- 


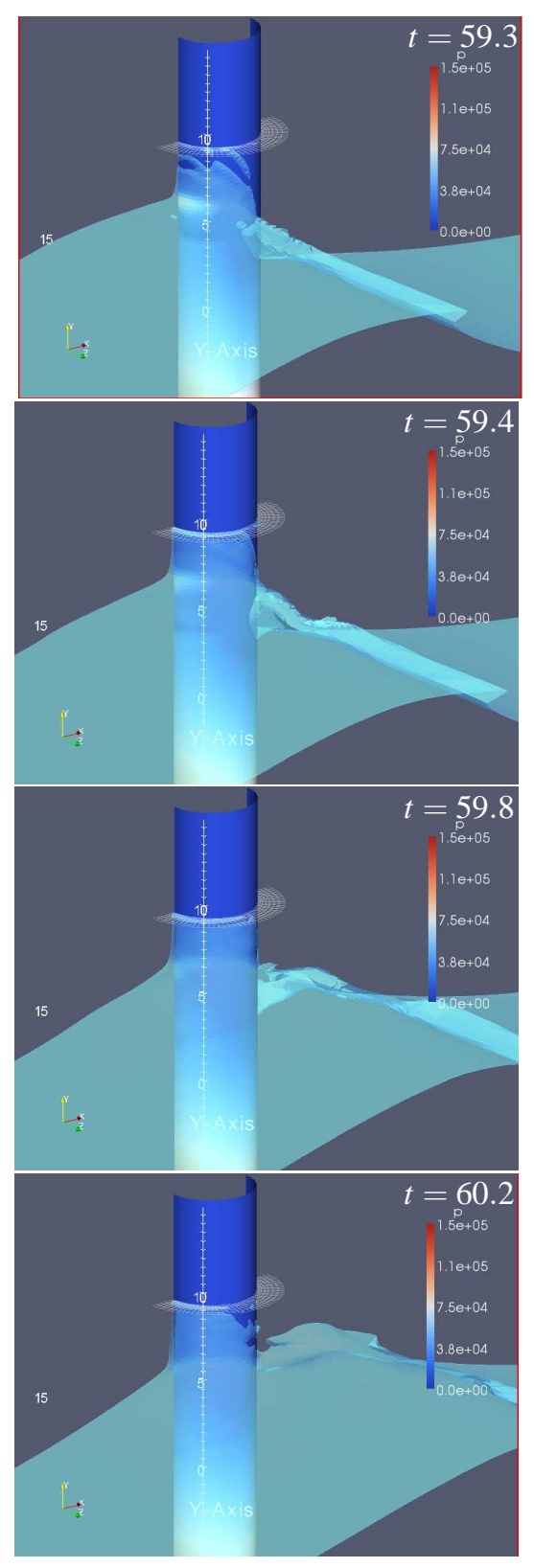

FIGURE 7. Upper panel: Wave shape and centre-plane air flow velocities prior to impact for $z_{p}=8.96 \mathrm{~m}$. The colours show the air speed in $[\mathrm{m} / \mathrm{s}]$. Middle and lower panel: Pressure field at two instants during the impact. The colours show the pressure in $[\mathrm{Pa}]$.

servations also apply for the focus position of $x=0 \mathrm{~m}$. Further, at this position and at $x=-50 \mathrm{~m}$ the second-order time series is seen to contain some high-frequency components which are not present in the CFD solution. This difference in high-frequency content might explain the difference in the trough elevation and may be due to insufficient spatial resolution of the shortest waves.
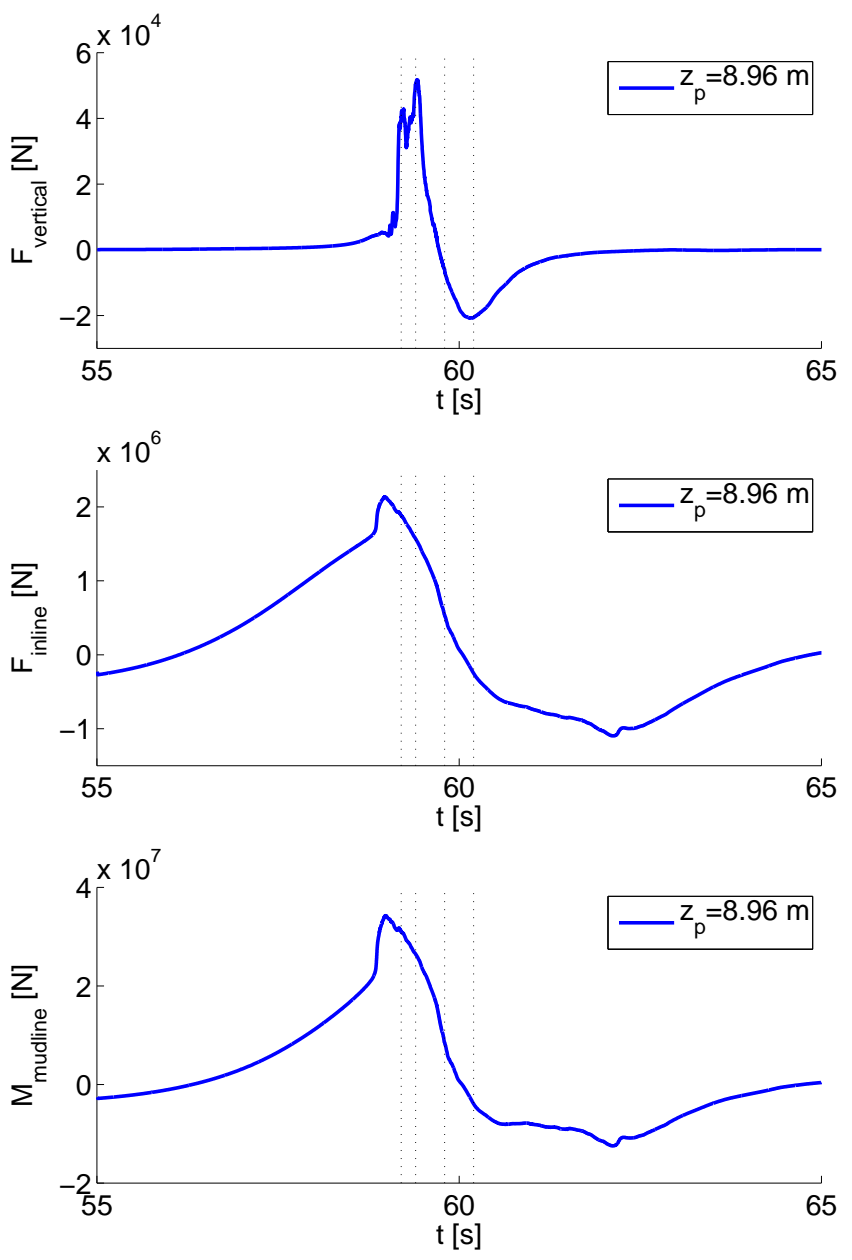

FIGURE 8. Time series for vertical force on platform (upper panel), in-line force (middle panel) and overturning moment (lower panel). $z_{p}=8.96 \mathrm{~m}$. Time instants for snapshots in figure 8 are marked by vertical dotted lines.

However, for the main focused wave crest elevation at $x=0 \mathrm{~m}$, a fine match between the second-order theory and the numerical solution is observed. The 2D incident wave field was chosen for all the $3 \mathrm{D}$ impact computations of the present paper.

\section{Platform level of $12.08 \mathrm{~m}$}

Figure 5 shows four snapshots of the wave impact for a platform level of $12.08 \mathrm{~m}$. Time series for the vertical force on the platform, the global in-line force and the global overturning moment are shown in figure 6 , where the time instants of the four snapshots are marked by vertical dotted lines.

The frame of $t=58.8 \mathrm{~s}$ shows the wave front prior to impact at an early stage of overturning. At $t=58.9 \mathrm{~s}$, the overturning crest has impacted on the monopile front and generated a pro- 


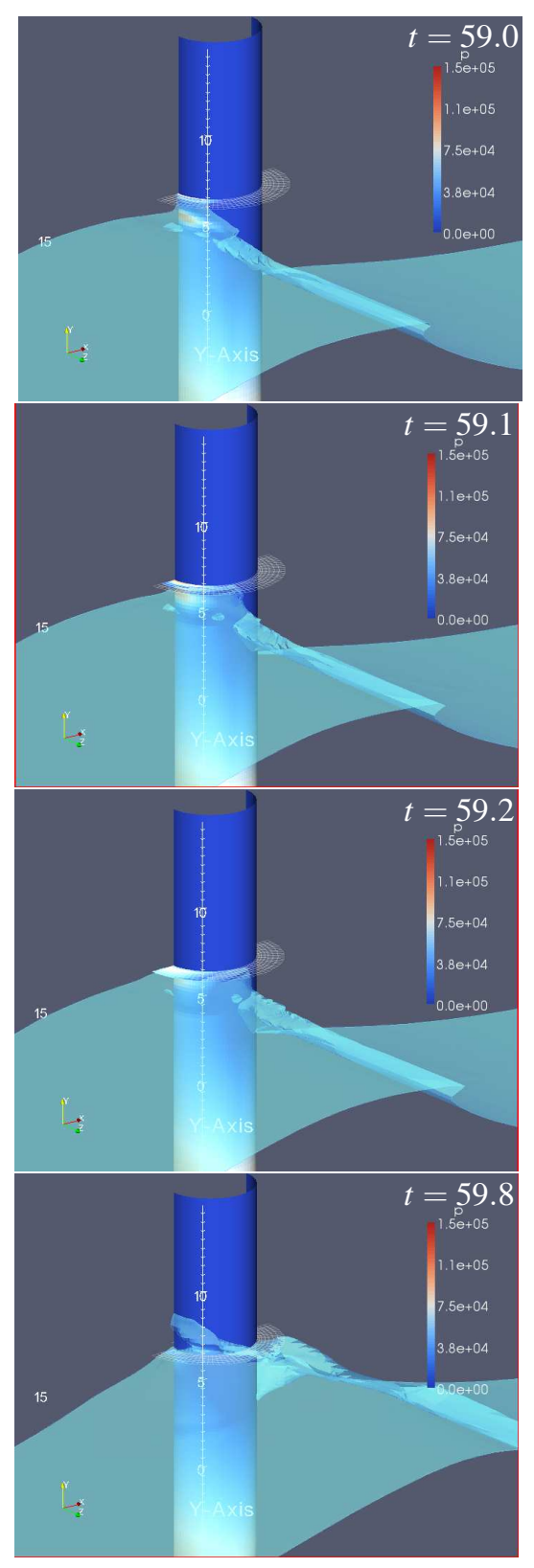

FIGURE 9. Upper panel: Wave shape and centre-plane air flow velocities prior to impact for $z_{p}=6.04 \mathrm{~m}$. The colours show the air speed in $[\mathrm{m} / \mathrm{s}]$. Middle and lower panel: Pressure field at two instants during the impact. The colours show the pressure in $[\mathrm{Pa}]$.

nounced slamming pressure on the cylinder face. The maximum in-line force is reached at $t=59.0 \mathrm{~s}$. At this instant the run-up process has been initiated, visible as a thin sheet of water with no significant pressure situated above the region of strong impact pressure. In the numerical solution, the pressure has a magnitude of $100 \mathrm{kPa}$. Note, however, that the numerical pressures shown
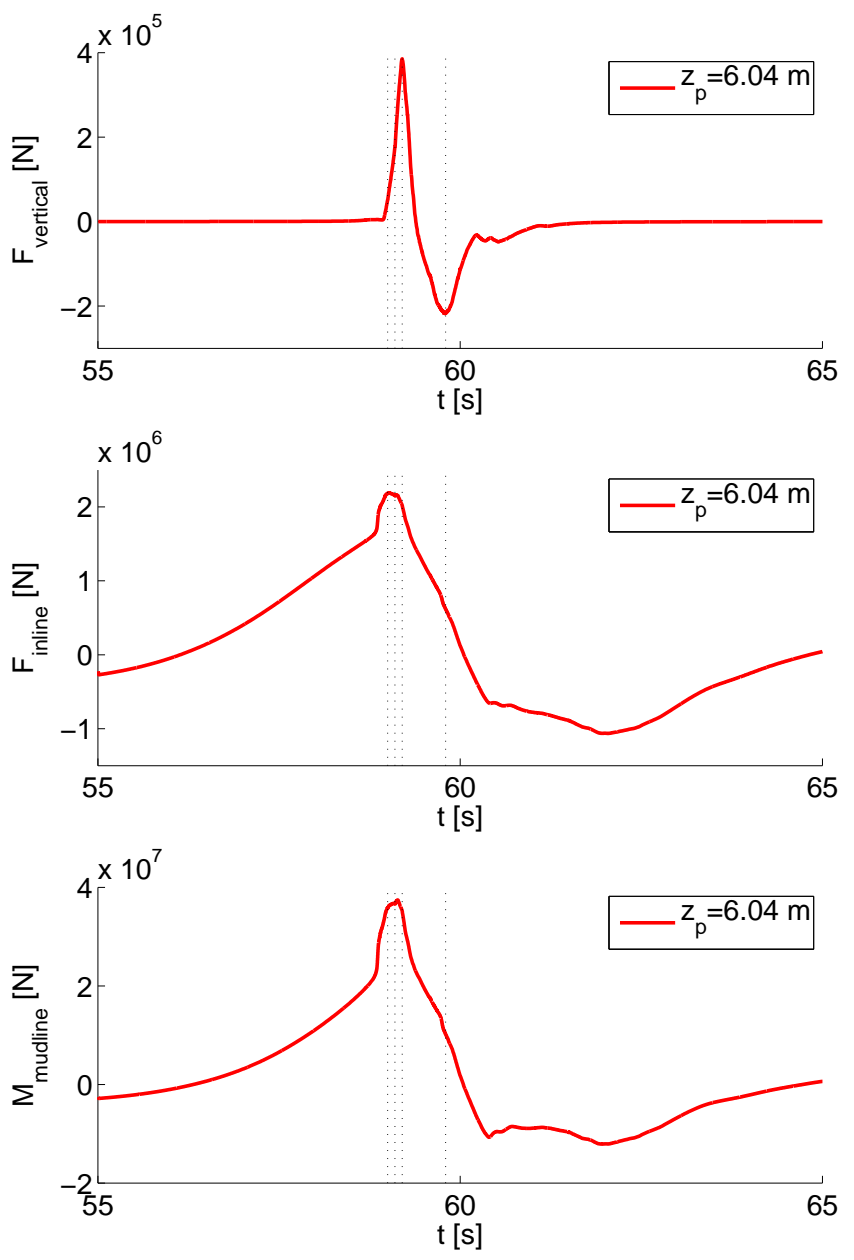

FIGURE 10. Time series for in-line force (upper panel), overturning moment (middle panel) and vertical force on platform (lower panel). $z_{p}=6.04 \mathrm{~m}$. Time instants for snapshots in figure 9 are marked by vertical dotted lines.

are likely to be grid-dependent, as violent wave impact pressures are generally strongly sensitive to grid spacing. For the less sensitive integrated measure of in-line force, Bredmose \& Jacobsen [10] demonstrated that the present grid resolution is sufficient for grid-independence. For the platform level of $12.08 \mathrm{~m}$, the platform is only reached by minor amounts of water. The vertical force is small, with a magnitude for the maximum value of $27 \mathrm{kN}$, see figure 6 . An example of run-up water in touch with the platform is visible in the fourth frame from $t=59.6 \mathrm{~s}$.

From the time series of figure 6, the maximum in-line force is 2.1 MN. A significant rise in the in-line force, from 1.7 MN to $2.1 \mathrm{MN}$ is associated with the arrival of the overturning front. For the overturning moment, a similar rise from $23 \mathrm{MNm}$ to the maximum value of $34 \mathrm{MNm}$ is seen. This highlights the significant forces associated with breaking wave impacts. 


\section{Platform level of $8.96 \mathrm{~m}$}

For the smaller platform height of $z_{p}=8.96 \mathrm{~m}$, snapshots of the flow and time series of the vertical platform force, in-line force and overturning moment are shown in figure 7-8. This platform level is lower than the run-up height of the impact and a vertical impact on the deck is obtained. As the incident wave is identical for all the three cases of platform height, the initial impact with the monopile is identical to the case of $z_{p}=12.08 \mathrm{~m}$. Hence the snapshots for the present case are chosen to illustrate the flow associated with the platform impact. At $t=59.2$ the first run-up water has reached the platform level and lead to an initial rise in vertical deck load. The maximum vertical load of $51 \mathrm{kN}$ occur between $t=59.4 \mathrm{~s}$ and $t=59.5 \mathrm{~s}$ and is associated with significant pressures in the corner region between the monopile front and horizontal deck. The frame of $59.8 \mathrm{~s}$ shows the impact at a more evolved state where the main wave has moved away from the structure. The vertical deck force is close to zero, although the sheet of run-up water is still present at the monopile front. This is also the case for $t=60.2 \mathrm{~s}$. Further, at this instant the vertical force on the platform is negative $(-20 \mathrm{kN})$. This downward force is associated with the exit flow of water after its contact with the platform and is a normal feature for wave-indeck impacts, see e.g. Kendon et al [16].

\section{Platform level of $6.04 \mathrm{~m}$}

Computational results for the platform level of $z_{p}=6.04 \mathrm{~m}$ are presented in figures 9-10. This level is very close to the crest elevation of the incident wave and the impact obtained is therefore almost a wave-in-deck type impact. Already at $t=59.0 \mathrm{~s}$, the time of maximum in-line force, significant pressures occur on the platform, caused by the run-up of water. The region of pressure exposition becomes larger as the impact evolves, as seen for $t=59.1 \mathrm{~s}$. The overturning moment and vertical force are maximum at $t=59.2 \mathrm{~s}$. At this instance a strong pressure is seen underneath the platform. The magnitude is about $85 \mathrm{kPa}$, which is about $40 \%$ of the still water hydrostatic pressure at the sea bed. The vertical force on the platform is significantly larger than for the previous cases with a maximum of $380 \mathrm{kN}$. The coincidence of time for the peak values of overturning moment and vertical force indicates that the platform impact leads to an increase in the the overturning moment. As for the previous case, a strong downward force on the platform occur after the initial upward load. At $t=59.8 \mathrm{~s}$, the downward force is at its maximum of $-200 \mathrm{kN}$. The corresponding frame shows that there is widespread contact between the fluid and the platform.

\section{Comparison of impacts, forces and moments}

Comparative plots of the vertical platform force, global inline force and global overturning moment are shown in figure 11. Results from two additional computations of $z_{p}=(7.08,10.0) \mathrm{m}$ are included.
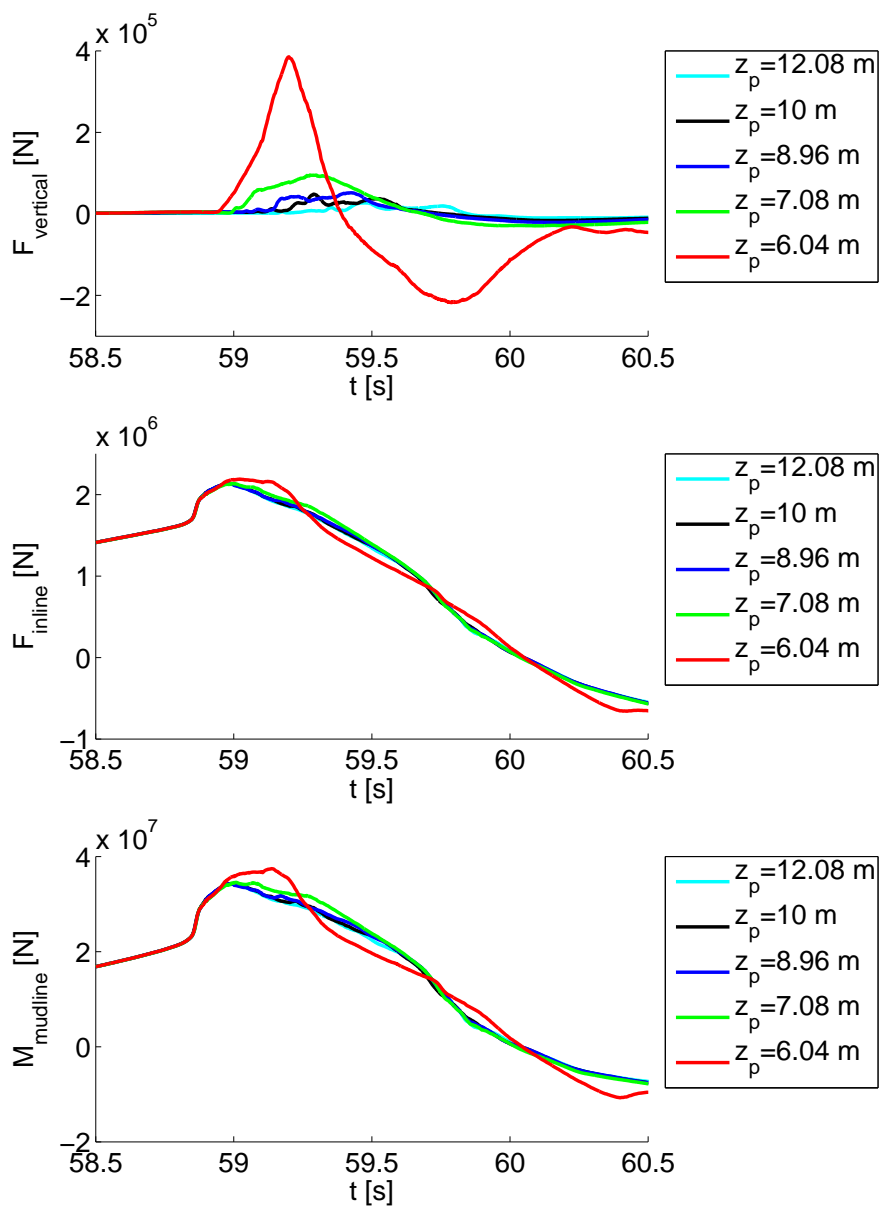

FIGURE 11. Comparison of vertical platform impact force (upper panel), in-line force (middle panel) and overturning moment (lower panel) for the five different platform levels.

As expected, the vertical impact force is largest for the lowest platform levels. For $z_{p}=(6.04,7.08) \mathrm{m}$, the computed vertical peak forces are $(380,95) \mathrm{kN}$. These values make out $(18 \%, 5 \%)$ of the typical peak in-line force of the middle panel, respectively. For the platform levels of $z_{p}=$ $(8.96,10.0,12.08) \mathrm{m}$, the maximum vertical force is $51 \mathrm{kN}$ or smaller for the present computations. Subsequent to the main positive vertical impact force, all impacts show a downward force that decays slowly towards zero. This downward force is associated with the exit flow away from the platform.

Time series for in-line force are compared in the middle panel. Until the impact with the platform, the in-line force history is identical for all the computations. For $z_{p}=6.04 \mathrm{~m}$, the vertical impact at the platform leads to a slight increase in the in-line force from 2.13 MN to 2.19 MN. The additional in-line force is due to the horizontal action of the pressure in the corner between the platform and the monopile front caused by the ver- 
tical impact. Further, from the time series plot, the duration of the maximum in-line force is increased. This leads to an increase in the impulse load on the monopile. Similar, though less significant behaviour is seen for the case of $z_{p}=7.08 \mathrm{~m}$, while the higher platform levels do not lead to changes of the in-line force.

The dependence of the maximum overturning moment to the platform level is similar to that of the in-line force. The differences due to the platform impacts, however, are amplified due to the long moment arm for the horizontally acting pressures in the corner between the monopile and the platform. Thus for $z_{p}=6.04 \mathrm{~m}$, the platform impact leads to an increase in overturning moment from 34.2 $\mathrm{MNm}$ to $37.4 \mathrm{MN}$ with associated extension of its duration. The same effects apply for $z_{p}=7.08 \mathrm{~m}$, although less pronounced due to the weaker vertical impact pressures.

\section{Assesment of grid effects}

Bredmose \& Jacobsen [10] found that a grid with a cell size of $\mathrm{d} r \times r \mathrm{~d} \theta \times \mathrm{d} z=(0.18 \times 0.18 \times 0.31) \mathrm{m}^{3}$ on the face of the monopile was sufficient for practical convergence of the inline force from breaking wave impacts. The present grid of 691000 cells is a refined version of this grid with a cell size of $0.12 \times 0.18 \times 0.21 \mathrm{~m}^{3}$ on the monopile face. Grid-independency of the results has been assessed by reproduction of the case for a deck level of $8.96 \mathrm{~m}$ on a further refined grid where all cell sizes where reduced by a factor of 1.4 in all three directions. The resulting grid consists of 1924000 cells with a cell size of $0.087 \times 0.13 \times 0.15 \mathrm{~m}^{3}$ at the face of the structure. On that grid a maximum inline force of $2.01 \mathrm{MN}$ and a maximum overturning moment of $32.9 \mathrm{MNm}$ were found. However, at this refined grid, the point of wave overturning occur at a position downstream of the monopile, as illustrated on figure 12. Hereby the two numerical grids lead to two different wave impacts and a direct comparison of the subsequent platform impacts has limited value. While on the fine grid, a set of computations with an overturning wave of similar nature as those of the coarse grid can be obtained by adjustment of the incident wave amplitudes, proper grid convergence requires identical boundary conditions for the different grids. A clarification of the grid-sensitivity of the point of overturning and the achievement of fully grid-independent results is thus left for future work. We note that although gridconvergence for the present computations has not been obtained, the results do provide a consistent data set for the study of vertical platform impact from an overturning wave and the influence of the platform level.

\section{SUMMARY AND DISCUSSION}

A numerical investigation into monopile wave impacts with subsequent vertical impact on inspection platforms has been carried out for a depth of $20 \mathrm{~m}$. The impacting waves have been

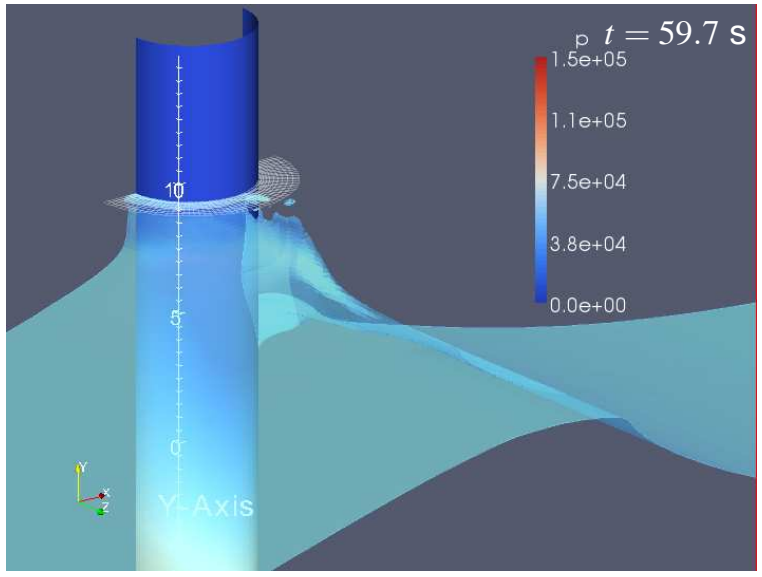

FIGURE 12. Solution for a platform level of $z_{p}=8.96 \mathrm{~m}$ obtained on a refined numerical grid. The wave overturns at a point downstream from the structure.

obtained by application of second-order focused wave groups. Two-dimensional test computations of the incident waves have been undertaken to decide on the final linear amplitudes. The incident wave was chosen such that an overturning impact would occur at the front of the monopile. A comparison of the numerically generated waves to the second-order wave generation signal has shown a good match for the crest elevation of the main wave in the focus point.

For the impact on the monopile, a maximum in-line force of 2.1 $\mathrm{MN}$ and a maximum overturning moment of $34 \mathrm{MNm}$ have been found prior to the vertical deck impact. A sharp rise towards the maximum loads occur at the arrival of the overturning wave front. For the conducted computations, the subsequent impact with the horizontal platform leads to vertical forces of magnitude $51 \mathrm{kN}$ or smaller, for platform levels that exceed $9 \mathrm{~m}$ above still water level. Larger forces with notable contributions to the inline force and overturning moment have been found for lower platform levels. For a platform level of $7.08 \mathrm{~m}$ above still water level, a vertical peak force of $95 \mathrm{kN}$ has been found. This is about $5 \%$ of the maximum in-line force for that particular impact. For the smaller platform elevation of $6.04 \mathrm{~m}$, an almost wave-in-deck type impact occur with a maximum vertical force of $380 \mathrm{kN}$ and with significant contribution to the overturning moment of the structure.

It should be noted that the present computations have been carried out on a grid that resolves the region around the monopile with cells of size $\mathrm{d} r \times r \mathrm{~d} \theta \times \mathrm{d} z=(0.12 \times 0.18 \times 0.21) \mathrm{m}^{3}$. While Bredmose \& Jacobsen [10] found that the in-line force was converged at slightly coarser resolution, a dependency to the grid resolution for the position of wave overturning has been found. Grid-convergence for the shape of the impacting wave and the results for inline force, overturning moment and vertical deck 
loads has therefore not been demonstrated on the present grid and is left for future work.

While the wave impacts of the present study are overturning, it should also be noted that more violent wave impacts might occur for other phase combinations of the linear wave components than applied here to obtain a crest-focused wave. Multidirectional waves or special topography may lead to the emergence of impacts of larger violence and thus larger loads on the monopile and the inspection platform.

Despite these notions, the present computations illustrate the potential of CFD calculation of violent wave loads. While simpler methods such as the Morison equation [17] often give good estimates of the forces on monopiles from non-breaking waves of moderate amplitude, impact loads of the present type cannot be estimated with this approach, as the vertical load-generating flow is a result of wave-structure interaction. Further, as the vertical impact loads are of short duration and generate short-duration contributions to the overturning moment and in-line force, the vertical impacts may be able to excite structural ringing at unexpected high frequencies. An accurate prediction of such loads is therefore important for practical design.

\section{REFERENCES}

[1] Damsgaard, M., Gravesen, H., and Andersen, T. L., 2007. "Design loads on platforms on offshore wind turbine foundations with respect to vertical run-up". European Offshore Wind, Berlin, Germany, EWEA.

[2] Frigaard, P., Andersen, T. L., Ramirez, J. R. R., Sø rensen, S. P. H., Martinelli, L., Lamberti, A., Troch, P., de Vos, L., Kisacik, D., Stratigaki, V., Zou, Q., Monk, K., Vandamme, J., Damsgaard, M. L., and Gravesen, H., 2010. "Loads on entrance platforms for offshore wind turbines". In Proc. Hydralab joint III user meeting. Hannover.

[3] de Vos, L., Frigaard, P., and de Rouck, J., 2007. "Wave run-up on cylindrical cone-shaped foundations for offshore wind turbines". Coastal Engng., 51(1), pp. 17-29.

[4] Nielsen, A. W., Mortensen, S. B., and Jacobsen, V., 2008. "Numerical modelling of wave run-up on a wind turbine foundation". In Proc. 27th Int. Conf. Offshore Mech. Arctic Engng., Estoril, Portugal, ASME.

[5] Andersen, T. L., and Frigaard, P., 2006. Horns rev II. 2D model tests. impact pressures on horizontal and cone platforms. DCE Contract Report 4, Aalborg University.

[6] Andersen, T. L., and Brorsen, M., 2007. Horns rev II. 2D model tests. impact pressures on horizontal and cone platforms from irregular waves. DCE Contract Report 13, Aalborg University.

[7] Gravesen, H., 2006. Run-up assessment. design basis db1. Tech. rep., DONG Energy.

[8] Christensen, E. D., Bredmose, H., and Hansen, E. A., 2005.
"Extreme wave forces and run-up on offshore wind turbine foundations". In Proc. Copenhagen Offshore Wind.

[9] Bredmose, H., Skourup, J., Hansen, E. A., Christensen, E. D., Pedersen, L. M., and Mitzlaff, A., 2006. "Numerical reproduction of extreme wave loads on a gravity wind turbine foundation". In Proc. 25th Int. Conf. Offshore Mech. Arctic Engng., ASME.

[10] Bredmose, H., and Jacobsen, N. G., 2010. "Breaking wave impacts on offshore wind turbine foundations: Focused wave groups and cfd". In Proc. 29th Int. Conf. Ocean Offshore Arctic Engng., ASME.

[11] Hunt, A., Taylor, P., Borthwick, A., Stansby, P., and Feng, T., 2004. "Phase inversion and the identification of harmonic structure in Coastal Engineering experiments". In Proc. 29th Int. Conf. Coast. Engng., Lisbon 2004, B. L. Edge, ed., ASCE, pp. 1047-1059.

[12] Bredmose, H., Hunt-Raby, A., Jayaratne, R., and Bullock, G. N., 2010. "The ideal flip-through impact: experimental and numerical investigation". J. Engng. Maths., 67, pp. 115-136. Special commemmorative volume for Howell Peregrine.

[13] Sharma, J., and Dean, R., 1981. "Second-order directional seas and associated wave forces". Socity of Petrolium Engineers Journal, pp. 129-140.

[14] Hirt, C. W., and Nichols, B. D., 1981. "Volume of fluid (vof) method for the dynamics of free boundaries". $J$. Comp. Phys., 39.

[15] Jacobsen, N. G., 2011. "A full hydro- and morphodynamic description of breaker bar development". PhD thesis, DTU Mechanical Engng., Nils Koppels Allé, Building 403, DK2800 Kgs. Lyngby, Denmark. April 2011.

[16] Kendon, T., Baarholm, R., Pakozdi, C., Stansberg, C., Enger, S., and Berthelsen, P., 2010. "Wave-in-deck impact: Comparing cfd, simple methods, and model tests". In Proc. 29th Int. Conf. Ocean Offshore Arctic Engng., ASME. Shanghai, China.

[17] Morison, J. R., O’Brien, M. P., Johnson, J. W., and Schaaf, S. A., 1950. "The forces exerted by surface waves on monopiles". J. Petrol. Techn., 189, pp. 149-154.

\section{ACKNOWLEDGMENT}

This research was carried out as part of the Statkraft Ocean Energy Research Program, sponsored by Statkraft (www.statkraft.no). This support is gratefully acknowledged. Bo Terp Paulsen and Dalibor Cavar are thanked for stimulating discussions and help in compiling OpenFOAM at the Linux cluster of DTU Mechanical Engineering. 